\title{
A Novel Compact Dual-Polarized Antenna
}

\author{
Yong Cheng, ${ }^{1}$ Yadan $\mathrm{Li},{ }^{1}$ and Wenjun $\mathrm{Lu}^{2}$ \\ ${ }^{1}$ College of Electronic Science and Engineering, Nanjing University of Posts and Telecommunications, Nanjing, Jiangsu 210003, China \\ ${ }^{2}$ College of Communication and Information Engineering, Nanjing University of Posts and Telecommunications, \\ Nanjing, Jiangsu 210003, China \\ Correspondence should be addressed to Yadan Li; lyd2014ydl@163.com
}

Received 11 January 2016; Revised 10 April 2016; Accepted 8 May 2016

Academic Editor: Wenhua Yu

Copyright (C) 2016 Yong Cheng et al. This is an open access article distributed under the Creative Commons Attribution License, which permits unrestricted use, distribution, and reproduction in any medium, provided the original work is properly cited.

A novel compact dual-polarized antenna is proposed. The antenna has a $1.43 \%$ impedance bandwidth which is from $1801 \mathrm{MHz}$ to $1827 \mathrm{MHz}$ for return loss larger than $10 \mathrm{~dB}$. The isolation between the two ports is above $28 \mathrm{~dB}$ in the bandwidth, and the gain is $6.6 \mathrm{dBi}$. The proposed antenna not only consists of a full-planar structure, but also is easy to be fabricated for its simple structure. Additionally, a section of slots and slits is cut on the radiation patch to reduce the area of it to $54 \%$ compared with the conventional square patch.

\section{Introduction}

Recently in modern wireless communication systems and mobile communications base stations, dual-polarized antennas are widely used to achieve polarization diversity, which can increase the capacity and reduce the installation costs. This is because the use of a dual-polarized antenna can reduce multipath fading and double the utilization rate of the frequency spectrum $[1,2]$.

Dual-polarized antennas with various kinds of structure are designed in the past decades of years. Roughly, the dual-polarized antennas can be divided into two categories: crossed dipole antennas and patch antennas. The crossed dipole antennas have different feeding structures, including C-shape [3], dielectric loading [4], differently driven [5], and shorting metal posts [6]. These feeding structures have been used for high isolation between the two ports. These dualpolarized crossed dipole antenna designs have accomplished bandwidth improvement, radiation pattern control, and so on, while none of these crossed dipole antennas has a fullplanar configuration.

The dual-polarized patch antennas normally have a multilayer structure which may include coupling slots and Lshaped probe [7] or meandering probe [8], or a feeding network $[9,10]$ proposing a dual-polarized microstrip patch antenna fed through $\mathrm{H}$-shaped coupling slots, which can achieve high isolation and low cross-polarization. A simple dual-polarized antenna achieved by using proximity-coupled feedings was presented in [11]; the antenna achieves the bandwidth of $17 \%$ and an isolation of below $30 \mathrm{~dB}$, but the frequency range from $3.07 \mathrm{GHz}$ to $3.81 \mathrm{GHz}$ is not suitable for mobile communications. A compact dual-polarized wideband patch antenna array for the unlicensed $60 \mathrm{GHz}$ band is designed in [12]. It provides a wide bandwidth for wireless high data rate communication systems while its fabrication process is very complex. Obviously these dual-polarized patch antennas with a multilayer structure have a complicated configuration. To improve those, a full-planar dual-polarized patch antenna with a simple configuration is proposed in this paper.

Good properties, such as high isolation and low crosspolarization levels, are necessary in a dual-polarized antenna, while the sizes are expected to be smaller by the public. Reference [13] proposes a double-polarization base station antenna; the antenna consists of two broadband base station antenna units, which make it has a large size. To reduce the area of the patch antenna, many methods have been used. Among them the most common one is to cut slots on the patch. Reference [14] proposes a single-feed circularly polarize patch antenna; the antenna uses U-slot loaded patch technique to effectively reduce the resonant frequency. In [15], there are two mirror imaged slots placed at the back of each 
radiating element in ground plane for reducing operating frequency while maintaining the patch size. In [16], a novel single-feed circularly polarized microstrip antenna is proposed which uses a cross slot in the center of the patch and four slits on the edge to reach compact size. Besides using slots, some other technologies also had been taken. In $[17,18]$, the proposed antennas used substrates with large thickness and L-probe feeding structures were used to reach the impedance matching.

In this paper, we propose a full-planar dual-polarized antenna with a simple and more compact configuration operating at global system for mobile communication (GSM) frequency $1.8 \mathrm{GHz}$. The antenna consists of a single-layer structure and two coaxial probe feeds. It will be shown that this antenna has a $1.43 \%$ impedance bandwidth and has good isolation between two feeding ports. Additionally, the area of the patch is effectively reduced by using a section of slots and slits.

\section{Antenna Design}

This section describes the design of the dual-polarized antenna. The antenna is initially designed using heuristics and then the design is created by a commercial, electromagnetic field software HFSS. The profits of the proposed antenna can be optimized by adjusting the sizes of the structure.

The length $L$ of the typical microstrip patch antenna can be calculated by the following equation, where $\lambda_{g}$ is the guide wavelength on the substrate:

$$
L=\frac{\lambda_{g}}{2} .
$$

So, for the antenna without any slits or slots which works at $1.8 \mathrm{GHz}$, the length of the patch is about $39 \mathrm{~mm}$.

A set of slots and slits are cut on the radiation patch to reduce its area [19]. With the slots and slits, the length of the current streamlines of the fundamental mode is increased, which can lower the resonant frequency. In another sense, the antenna proposed can use patch with smaller area to get the same resonant frequency. In the abstract, the quantity and sizes of the slots and slits determine the dimensions of the patch.

Figure 1 shows the geometry of the proposed dualpolarized antenna. The proposed antenna is printed on a $60 \times 60 \mathrm{~mm}^{2}$ FR4 substrate which has a thickness of $1.6 \mathrm{~mm}$; relative permittivity $\varepsilon_{r}=4.4$ and dielectric loss tangent $\tan \delta=0.02$. A slotted square patch fed by two probes is on the front side of the substrate. On the back of the substrate is the ground plane with the same sizes as the surface of the substrate. The inner core of the coaxial cable is $1.2 \mathrm{~mm}$ in diameter while the outer core is $3 \mathrm{~mm}$ in order to achieve $50 \Omega$ characteristic impedance. The two feeding ports are on two mutually perpendicular axes and have the same length to the center of the patch.

After careful simulation by the software HFSS, a resonant frequency of $1.8 \mathrm{GHz}$ is obtained. The finally chosen dimensions of the proposed antenna are as follows: $x_{1}=11 \mathrm{~mm}$, $x_{2}=7 \mathrm{~mm}, x_{3}=7.95 \mathrm{~mm}$, and $x_{4}=8 \mathrm{~mm}$. The width of all of the slots and slits $w$ is $1 \mathrm{~mm}$. After simulation, with four Lshaped slots in the center and eight slits on the edges, the edge

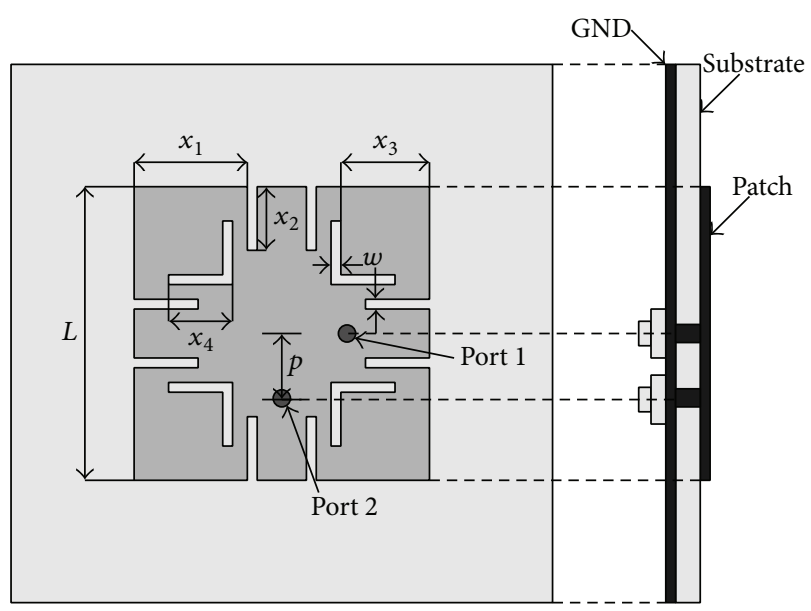

(a)

(b)

FIGURE 1: Geometry of the antenna: (a) front view; (b) lateral view.

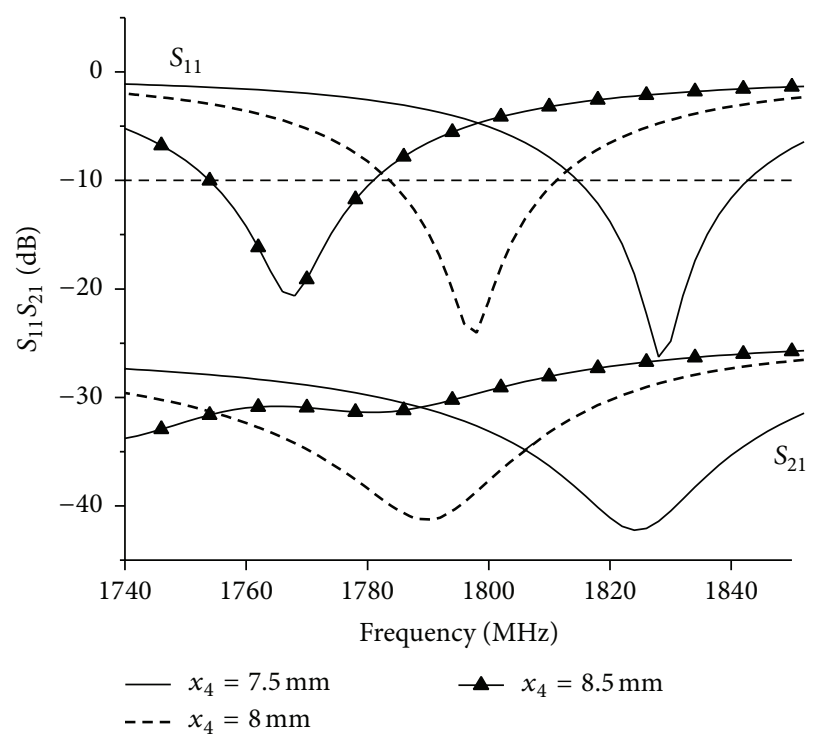

Figure 2: Simulated $S_{11}$ and $S_{21}$ with different values of $x_{4}$.

length $L$ is reduced to $28.5 \mathrm{~mm}$, which makes the area of the patch reduced to $54 \%$ compared with the conventional square patch.

The position of the ports, which is determined by the parameter $p$, influences impedance matching to a large extent. The parameter $p$ is carefully picked in simulation and set to $5.3 \mathrm{~mm}$.

\section{Simulation and Measurement}

The dimensions of the slots influence the resonant frequency a lot. Figure 2 shows $S_{11}$ and $S_{21}$ with different values of $x_{4}$. From the figure it is suggested that with increase of the length of the slots, the resonant frequencies of both $S_{11}$ and $S_{21}$ decrease. However, the slots cannot be too long. When $x_{4}$ is increased to $8.5 \mathrm{~mm}$, the isolation between two ports becomes 


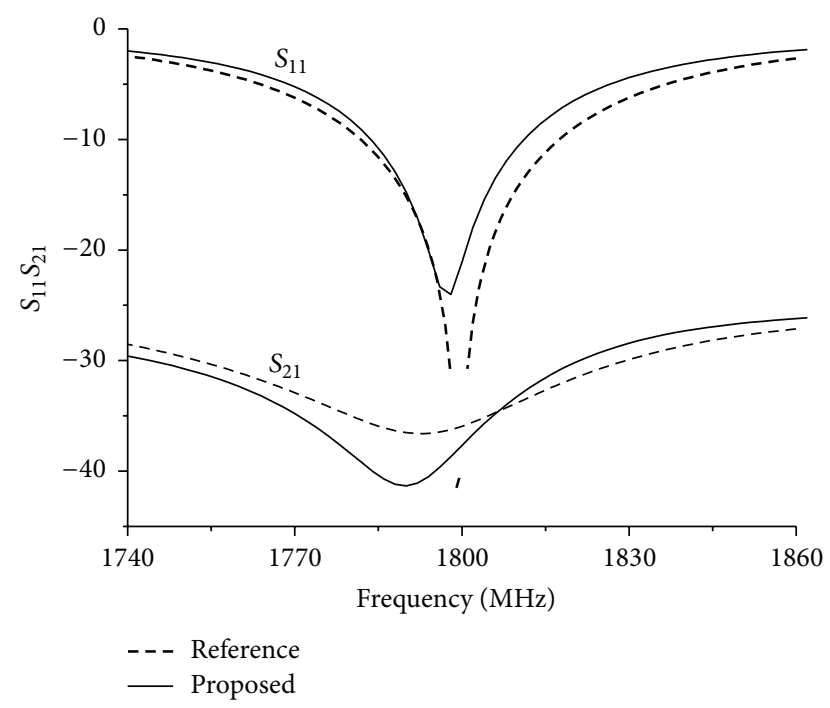

FIGURE 3: Simulated $S_{11}$ and $S_{21}$ of the proposed antenna and the typical one without any slots.

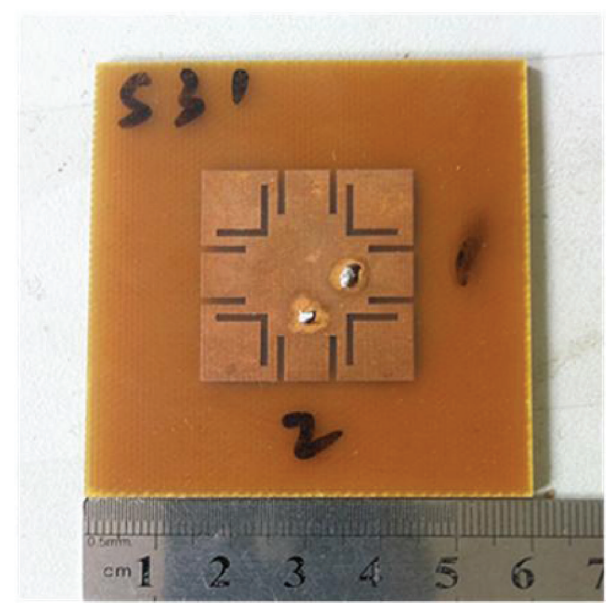

FiguRE 4: Fabricated proposed antenna.

weak and the return loss decreases a lot. At last, this parameter is selected as $8 \mathrm{~mm}$.

After careful simulation, the final dimensions of the proposed antenna are confirmed. A comparison of the proposed one is made with the typical microstrip patch antenna without any slots, as shown in Figure 3.

The isolation of the typical antenna as reference is above $32 \mathrm{~dB}$ over the working bandwidth. While the proposed one is above $34 \mathrm{~dB}$, which is slightly higher than the typical one.

The photograph of the fabricated proposed antenna is shown in Figure 4.

Figure 5 shows the simulated and measured return loss of the proposed antenna. As it is shown, the simulated antenna has a $1.5 \%$ impedance bandwidth which is $27 \mathrm{MHz}$ from $1784 \mathrm{MHz}$ to $1811 \mathrm{MHz}$ for return loss larger than $10 \mathrm{~dB}$. The simulated curves of $S_{11}$ and $S_{22}$ almost overlap because of the symmetrical structure of the antenna. The center frequency is $1800 \mathrm{MHz}$ where the top return loss is

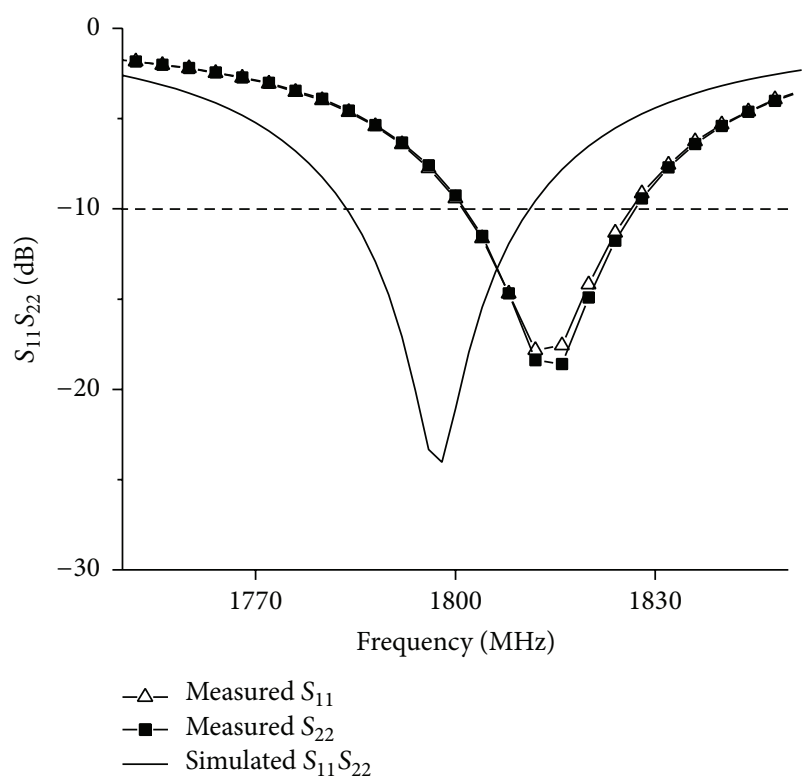

FiguRE 5: Simulated and measured return loss of the antenna.

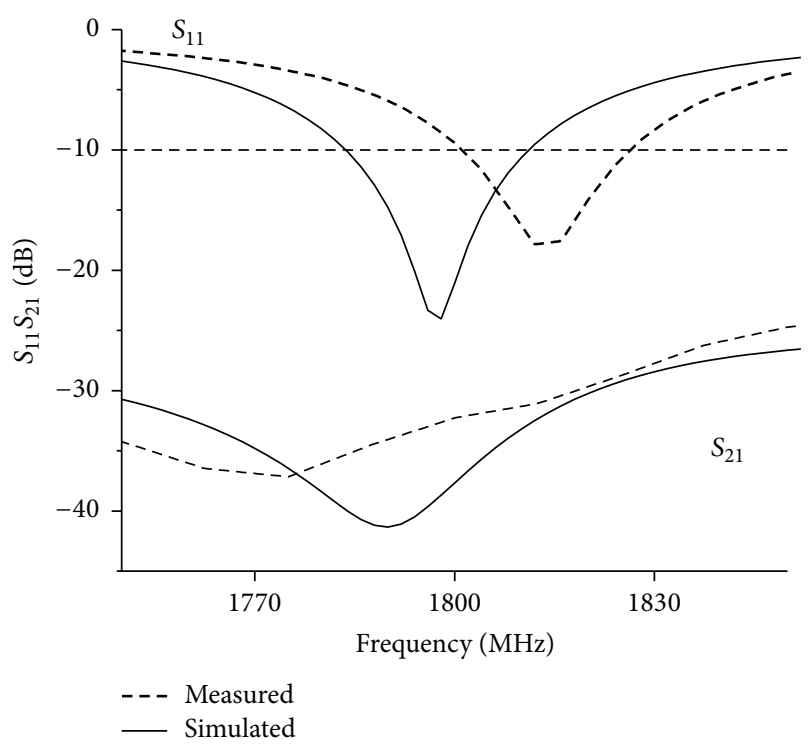

FIGURE 6: Simulated and measured $S_{11}$ and $S_{21}$ of the antenna.

$23.6 \mathrm{~dB}$. For the fabricated proposed antenna, the measured bandwidth is $26 \mathrm{MHz}$ from $1801 \mathrm{MHz}$ to $1827 \mathrm{MHz}$, and the top return loss at the center frequency $1814 \mathrm{MHz}$ is $18.6 \mathrm{~dB}$, which is smaller than the simulated result.

The isolation of the proposed antenna is illustrated in Figure 6. It shows that the simulated isolation is $38.6 \mathrm{~dB}$ at the center frequency $1800 \mathrm{MHz}$ and is above $34 \mathrm{~dB}$ in the whole $10 \mathrm{~dB}$ impedance bandwidth. As measured, the isolation of the fabricated antenna is $31 \mathrm{~dB}$ at the center frequency $1814 \mathrm{MHz}$ and is above $28 \mathrm{~dB}$ in the impedance bandwidth, which meets the design requirements. As for the difference between the measured and simulated center frequency, there are some reasons as follows: the actual permittivity of the substrate FR4 often ranges from 4.2 to 4.6 , whereas 4.4 is just 

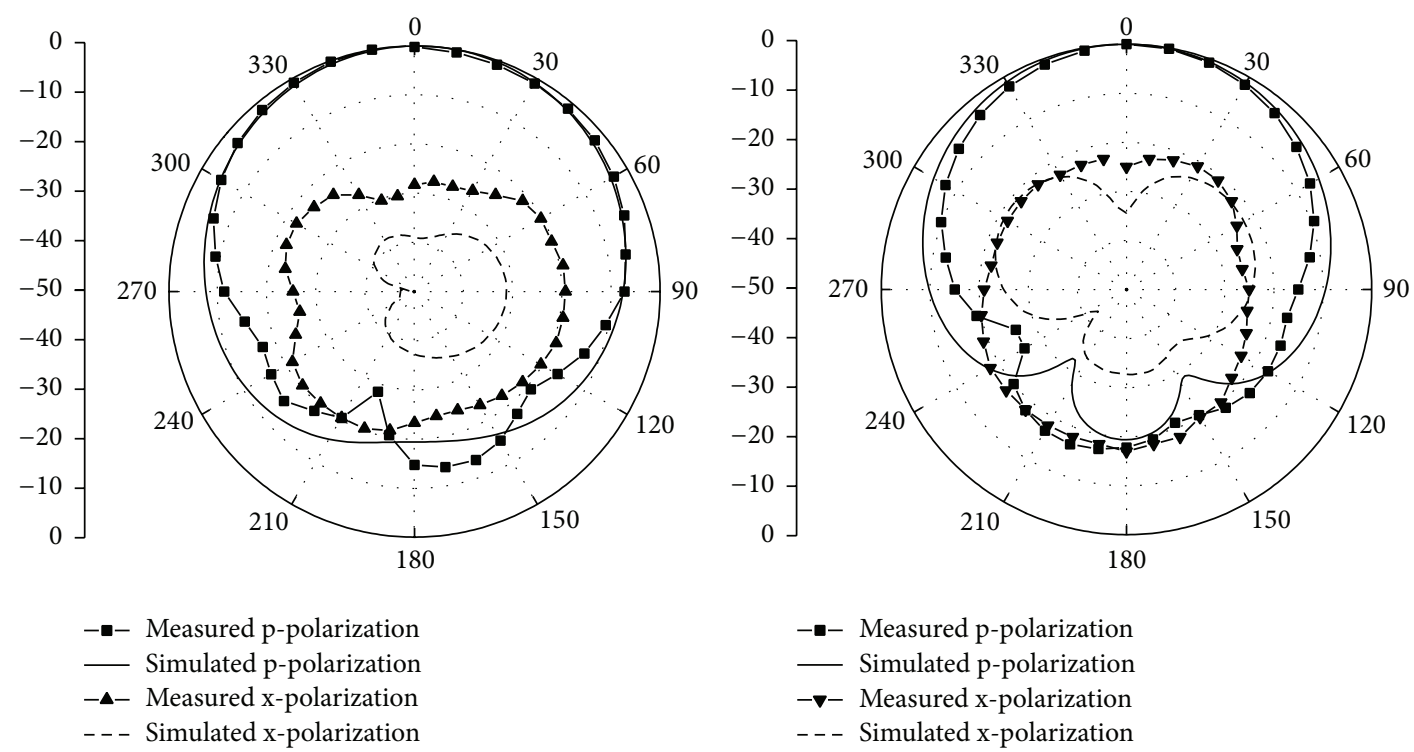

(b)

(a)

FIgURE 7: Radiation patterns of port 1: (a) E-plane; (b) $H$-plane.
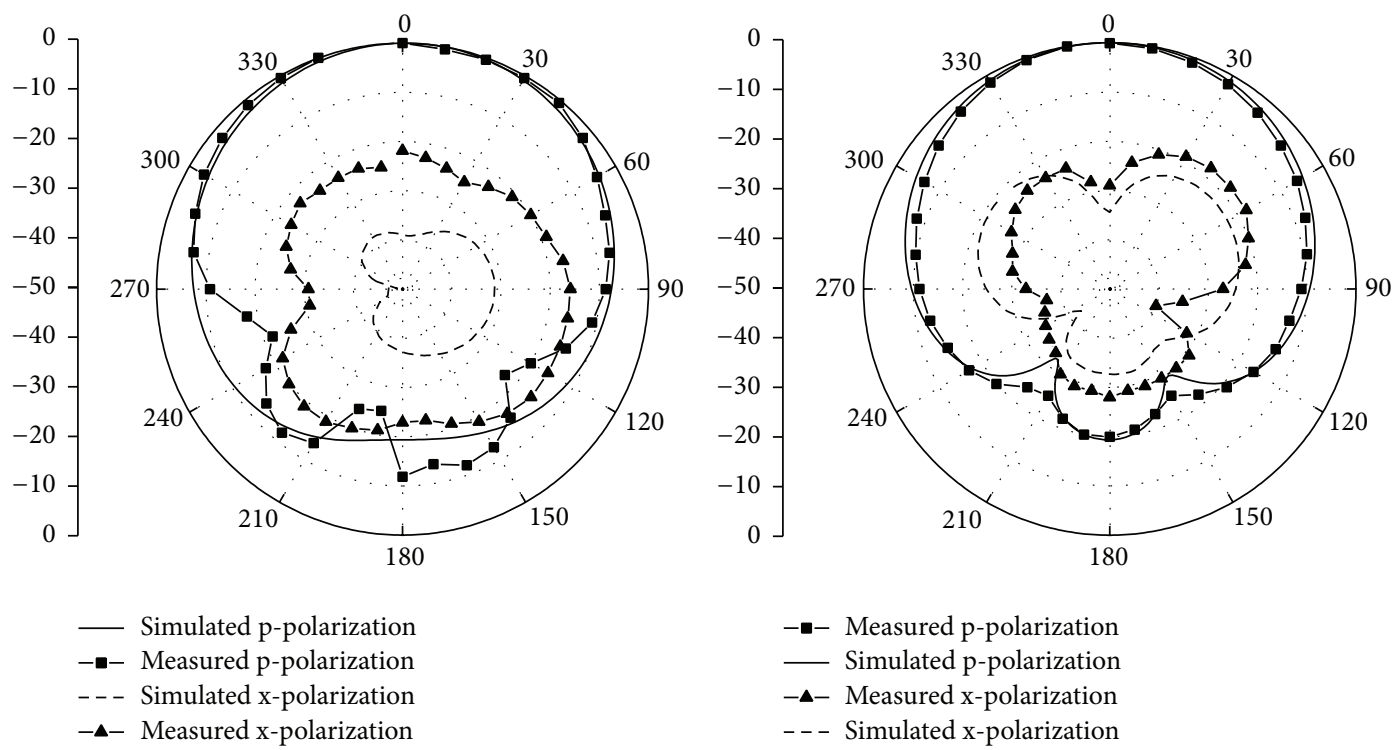

(a)

(b)

FIGURE 8: Radiation patterns of port 2: (a) $E$-plane; (b) $H$-plane.

selected to simulate. The fabrication process may also make some differences, which makes the results different between the simulated one and the measured. Besides, the welding technology of the coaxial cable may also bring some errors.

It is observed from Figures 7 and 8 that the simulated radiation patterns of port 1 are the same as the ones of port 2 for the symmetrical structure of the antenna. But there are some differences in the measured results because of the deviations in fabrication and measure. Figures 7 and 8 are the simulated and measured principle polarization ( $p$ polarization) and cross-polarization (x-polarization) patterns in case of being fed by port 1 and port 2. As it is shown, the differences between measured patterns and those simulated are not much except a part of the $\mathrm{x}$-polarization patterns has large deviations, which is due to the fact that the values are too small for the precision of measuring equipment to satisfy the demand. In the mass, the gain of $\mathrm{x}$-polarization is $20 \mathrm{~dB}$ lower than that of p-polarization, which meets the requirement of dual-polarization design. The gain of the antenna is $6.6 \mathrm{dBi}$.

The current distribution on the patch surface is displayed in Figure 9. From the figure it can be seen that the currents are mainly distributed around the edge of the slots and slits and 


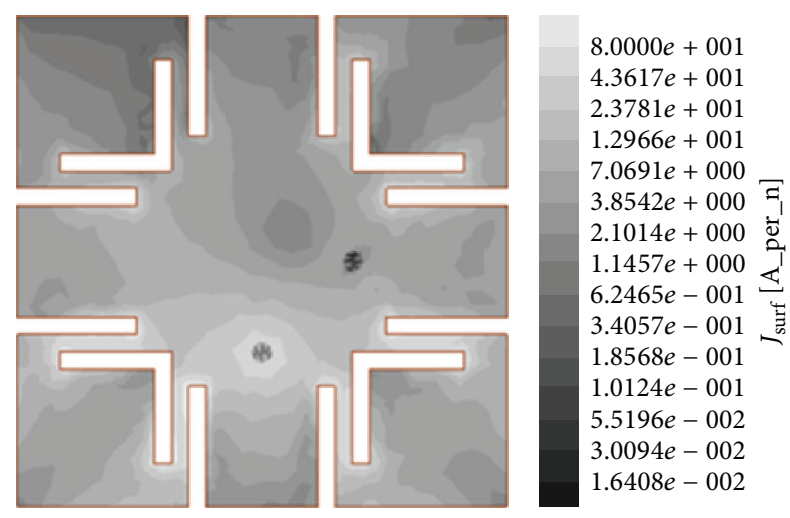

FIGURE 9: Simulated patch surface current magnitude distribution of phase 0 at $1.8 \mathrm{GHz}$.

at the corner of the patch the currents are weak. It indicates that the surface current path is effectively lengthened by the slots and slits.

\section{Conclusion}

A novel slotted dual-polarized planar antenna is presented in this paper. This antenna is fed by two mutually perpendicular ports and operates around $1.8 \mathrm{GHz}$. A set of slots are used to reduce the area of the radiation patch. The measured results suggest that the proposed antenna has a $26 \mathrm{MHz}$ bandwidth, in which the return loss is larger than $10 \mathrm{~dB}$ and the isolation is above $28 \mathrm{~dB}$, and a maximum gain of $6.6 \mathrm{dBi}$.

\section{Competing Interests}

The authors declare that there is no conflict of interests regarding the publication of this paper.

\section{Acknowledgments}

This work was supported in part by a project funded by the Priority Academic Program Development of Jiangsu Higher Education Institutions (PAPD), Jiangsu Natural and Science Foundation of Universities under Grant no. 13KJA510002, Research Project of Nanjing University of Posts and Telecommunications (208035), and National Natural Science Foundation of China under Grant no. 61427801.

\section{References}

[1] J. R. James and P. S. Hall, Eds., Handbook of Microstrip Antennas, Peregrinus, Stevenage, UK, 1989.

[2] L. M. Burns and C. L. Woo, "Dual orthogonal monopole antenna system," US Patent no. 5990838, 1999.

[3] B. Q. Wu and K.-M. Luk, "A broadband dual-polarized magneto-electric dipole antenna with simple feeds," IEEE Antennas and Wireless Propagation Letters, vol. 8, pp. 60-63, 2009.

[4] L. Siu, H. Wong, and K.-M. Luk, "A dual-polarized magnetoelectric dipole with dielectric loading," IEEE Transactions on Antennas and Propagation, vol. 57, no. 3, pp. 616-623, 2009.
[5] Q. Xue, S. W. Liao, and J. H. Xu, "A differentially-driven dualpolarized magneto-electric dipole antenna," IEEE Transactions on Antennas and Propagation, vol. 61, no. 1, pp. 425-430, 2013.

[6] S.-G. Zhou, P.-K. Tan, and T.-H. Chio, "Low-profile, wideband dual-polarized antenna with high isolation and low cross polarization," IEEE Antennas and Wireless Propagation Letters, vol. 11, pp. 1032-1035, 2012.

[7] Y.-X. Guo, K.-W. Khoo, and L. C. Ong, "Wideband dualpolarized patch antenna with broadband baluns," IEEE Transactions on Antennas and Propagation, vol. 55, no. 1, pp. 78-83, 2007.

[8] H.-W. Lai and K.-M. Luk, "Dual polarized patch antenna fed by meandering probes," IEEE Transactions on Antennas and Propagation, vol. 55, no. 9, pp. 2625-2627, 2007.

[9] S. K. Padhi, N. C. Karmakar, C. L. Law, and S. Aditya, "A dual polarized aperture coupled circular patch antenna using a CShaped coupling slot," IEEE Transactions on Antennas and Propagation, vol. 51, no. 12, pp. 3295-3298, 2003.

[10] S.-C. Gao, L.-W. Li, M.-S. Leong, and T.-S. Yeo, "Dual-polarized slot-coupled planar antenna with wide bandwidth," IEEE Transactions on Antennas and Propagation, vol. 51, no. 3, pp. 441-448, 2003.

[11] S. Gao and A. Sambell, "Broadband dual-polarized proximity coupled circular patch antenna," Microwave and Optical Technology Letters, vol. 47, no. 3, pp. 298-302, 2005.

[12] F. Wollenschläger, R. Stephan, L. Xia et al., "A compact dualpolarized wideband patch antenna array for the unlicensed $60 \mathrm{GHz}$ band," in Proceedings of the 5th European Conference on Antennas and Propagation (EUCAP '11), pp. 1873-1877, Rome, Italy, April 2011.

[13] J. M. Zhou, "A design of 45-degree dual-polarization broadband plane station antenna," International Journal of Antennas and Propagation, vol. 2015, Article ID 297521, 9 pages, 2015.

[14] K. Y. Lam, K.-M. Luk, K. F. Lee, H. Wong, and K. B. Ng, "Small circularly polarized U-slot wideband patch antenna," IEEE Antennas and Wireless Propagation Letters, vol. 10, pp. 87-90, 2011.

[15] M. F. Ismail, M. K. A. Rahim, M. R. Hamid, H. A. Majid, and M. F. M. Yusof, "Compact dual-fed slotted circular polarization antenna with reflector for RF energy harvesting," in Proceedings of the 7th European Conference on Antennas and Propagation (EuCAP '13), pp. 2096-2099, Gothenburg, Sweden, April 2013.

[16] S. Kumar, B. K. Kanaujia, A. Sharma, M. K. Khandelwal, and A. K. Gautam, "Single-feed cross-slot loaded compact circularly polarized microstrip antenna for indoor WLAN applications," Microwave and Optical Technology Letters, vol. 56, no. 6, pp. 1313-1317, 2014.

[17] J. Wu, X. Yang, Y. Yin, and F. Xu, "Wideband operations for compact single-fed circularly polarized microstrip antenna," Microwave and Optical Technology Letters, vol. 55, no. 6, pp. 1254-1257, 2013.

[18] T. Wu, H. Su, L. Gan, H. Chen, J. Huang, and H. Zhang, "A compact and broadband microstrip stacked patch antenna with circular polarization for $2.45-\mathrm{GHz}$ mobile RFID reader," IEEE Antennas and Wireless Propagation Letters, vol. 12, pp. 623-626, 2013.

[19] D. L. Nguyen, K. S. Paulson, and N. G. Riley, "Reduced-size circularly polarised square microstrip antenna for $2.45 \mathrm{GHz}$ RFID applications," IET Microwaves, Antennas and Propagation, vol. 6, no. 1, pp. 94-99, 2012. 


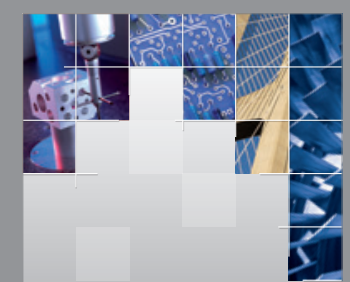

\section{Enfincering}
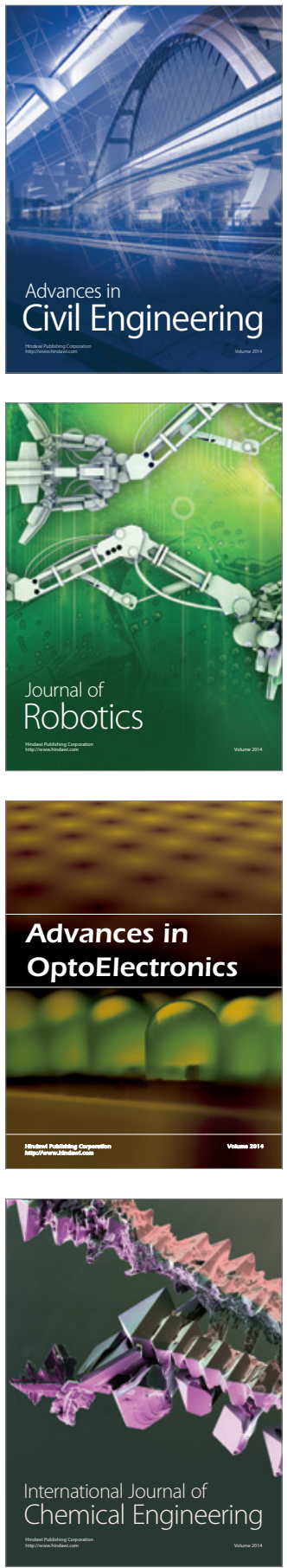

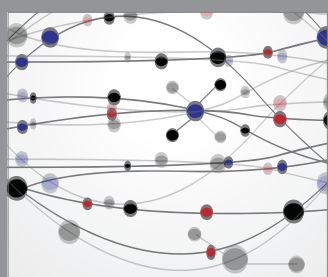

The Scientific World Journal

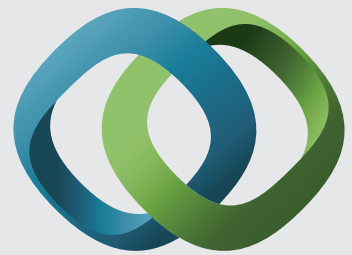

\section{Hindawi}

Submit your manuscripts at

http://www.hindawi.com
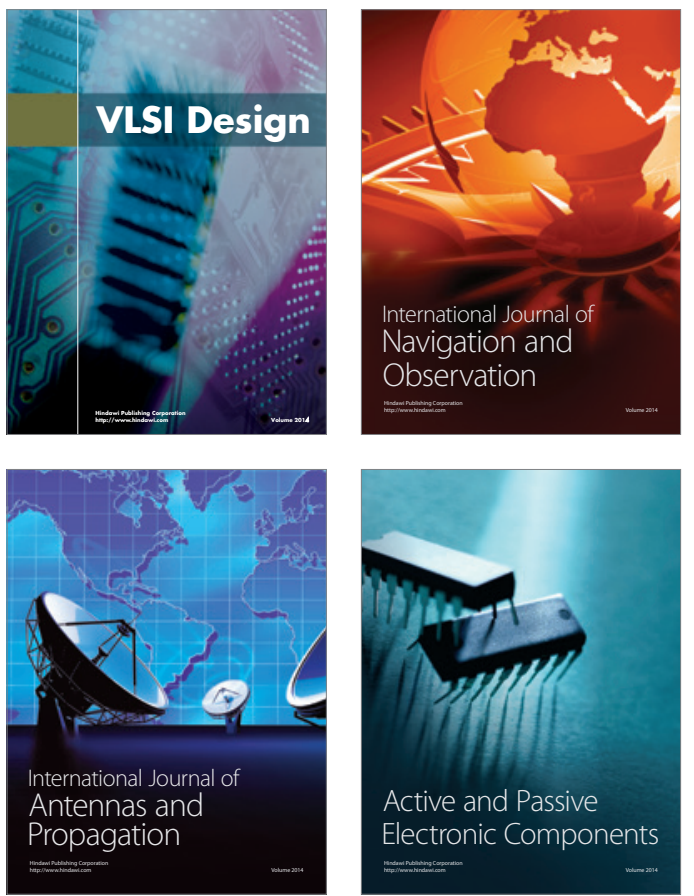
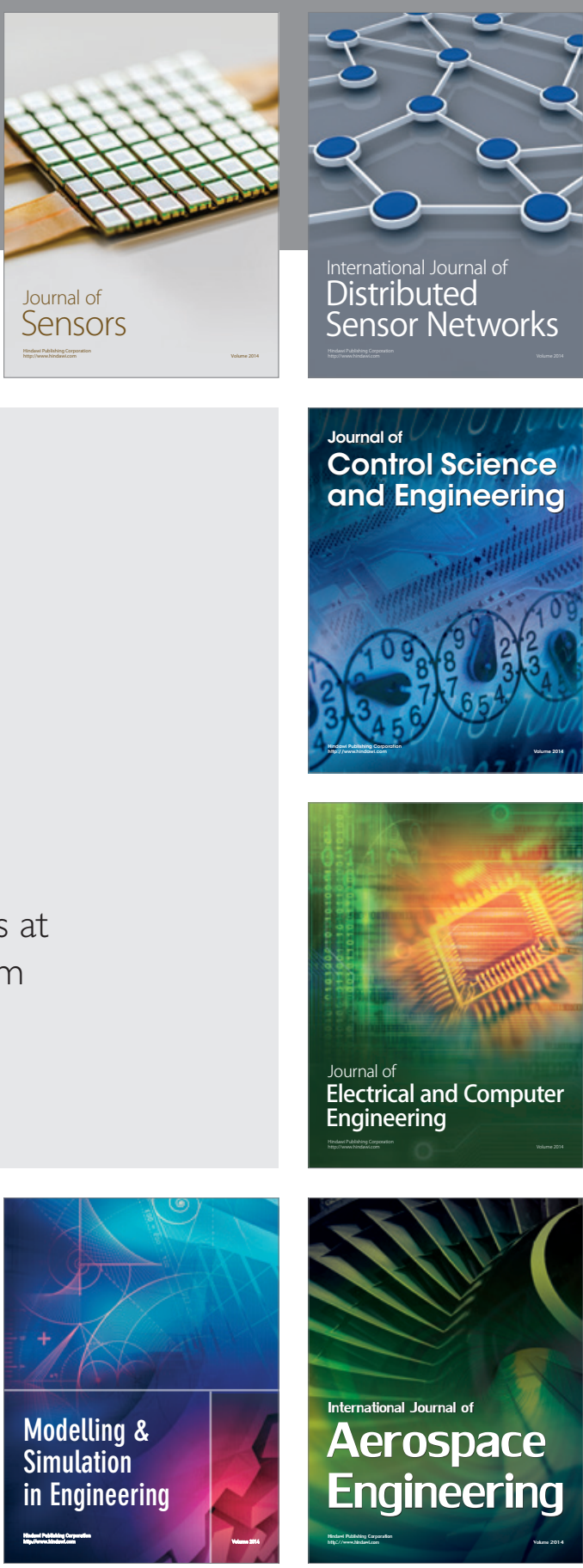

International Journal of

Distributed

Sensor Networks

Journal of

Control Science

and Engineering
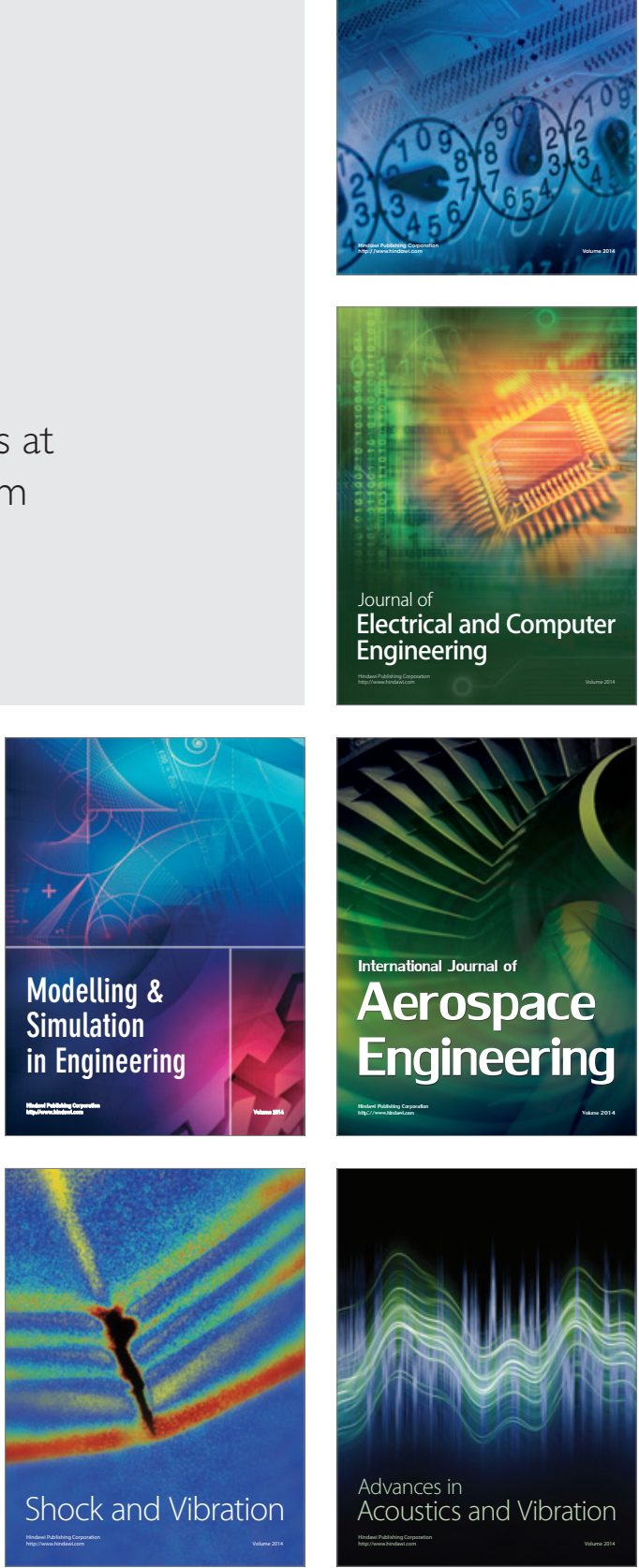